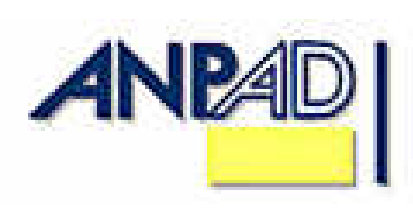

Disponível em http://www.anpad.org.br/rac

RAC, Curitiba, v. 13, n. 1, art. 8, p. 136-153, Jan./Mar. 2009

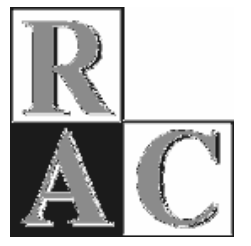

\title{
Oportunidades de Qualificação Profissional no Brasil: Reflexões a partir de um Panorama Quantitativo
}

\section{Opportunities for Professional Qualification in Brazil: Reflections Based on a Quantitative Study}




\section{RESUMO}

O objetivo deste trabalho foi realizar um mapeamento nacional das oportunidades de qualificação profissional e das organizações que mais investem nesse tipo de ação. Para tanto foi realizado survey com 1.150 instituições (públicas, privadas e do terceiro setor), em 115 municípios e 23 unidades federadas. A amostra foi probabilística, por conglomerado, com 50 questionários por UF, abrangendo a capital e municípios de médio e de pequeno porte (classificação IBGE/2004). Os resultados mostram que mais de um quarto das organizações não realiza ações de qualificação dos seus funcionários. O Índice de Oportunidades de Qualificação Profissional, criado neste estudo, apresentou correlação positiva com número de empregados, porte da organização e tempo de atuação no mercado. A análise de variância (ANOVA) apontou diferenças significativas entre as regiões brasileiras e entre as organizações públicas e privadas. As organizações de grande porte, com mais de 100 funcionários, mais de 22 anos no mercado e localizadas nas regiões Sul e Sudeste correspondem ao perfil que mais oferece oportunidades de qualificação. Esse panorama chama a atenção para a importância de políticas públicas, que facilitem o processo de capacitação das pessoas que atuam em organizações menores, que oferecem poucas oportunidades de qualificação.

Palavras-chave: oportunidades de qualificação; Treinamento e Desenvolvimento; organizações brasileiras.

\section{ABSTRACT}

The objective of this study was to make a national mapping of opportunities in professional qualification, identifying the characteristics of organizations that invest more in this type of action. The research design was a survey with 1,150 questionnaires sent to public, private and third sector institutions in 115 cities in 23 Brazilian states. The sample was probabilistic, due to conglomeration, with 50 questionnaires per state, including the capital city, medium size and small towns. The results show that $25 \%$ of the organizations do not provide any qualification opportunities to their employees. An Index of Professional Qualification Opportunities was created for this study, and this index showed a positive correlation with the number of employees, organization size and time established in the market. The variance analysis (ANOVA) indicated significant differences of the indices comparing different Brazilian regions and public or private organizations. The characteristics of the organizations that most offer more qualification chances are: big organizations, with more than 100 employees, more than 22 years in the market and located in the South and Southeastern Brazilian regions. In this scenario, there would be important actions, especially public policies, which facilitate the qualification of the people who work in smaller organizations.

Key words: qualification opportunities; Training and Development; Brazilian organizations. 


\section{INTRODUÇÃO}

A gestão de pessoas no ambiente organizacional tem-se tornado objeto de estudo e de atuação prática cada vez mais desafiante. Fenômenos como a globalização, a terceirização, os novos modelos de gestão, os avanços tecnológicos, o crescimento do desemprego e a automação têm provocado significativas mudanças para as organizações e para o trabalho e exigido qualificação constante dos profissionais. Diante desse cenário, as pressões competitivas realçam ainda mais o interesse na aprendizagem como determinante do desempenho e como fator de sobrevivência das organizações. Expressões como diferencial humano, capital intelectual e manutenção de talentos mostram que as pessoas têm sido vistas como fundamentais no processo de desenvolvimento e de sustentabilidade das organizações.

Salas e Cannon-Bowers (2001) mostram que nos Estados Unidos os investimentos em ações de Treinamento, Desenvolvimento e Educação [TD\&E] variam anualmente entre 55,3 bilhões e 200 bilhões de dólares - algo correspondente a cerca de $1 \%$ do Produto Interno Bruto daquele país em 2001. Na Europa, estudo apresentado por Bassanini, Booth, Brunello, De Paola, Leuven (2005), mostra que dos 26 países europeus pesquisados, os que apresentam maior investimento por empregado são Dinamarca, Suécia, Holanda, França, Finlândia e Bélgica, com valores que variam de 41 (Romênia) a 1.132 euros (Dinamarca). Em relação ao percentual investido em ações de T\&D considerando os custos totais, lideram o ranking os mesmos países; a Irlanda substitui a Bélgica, com variações de 0,5 a $3 \%$ dos custos totais, respectivamente para a Romênia e para a Dinamarca. No Brasil, não há estimativas do valor investido em ações educacionais nas organizações, mas sabe-se que cada vez mais ênfase tem sido dada ao assunto. Porém, em que medida as organizações estão investindo na qualificação dos seus profissionais? Que tipo de oportunidades de qualificação as organizações oferecem? Os empresários estão dispostos a contratar pessoas com menos experiência e investir no seu processo de aprendizagem? Essas são algumas perguntas a que se buscou responder com a realização desta pesquisa, cujo objetivo foi realizar um mapeamento nacional das ações que favorecem a qualificação profissional, realizadas por organizações no Brasil, com a identificação do perfil de instituição que mais tem investido nesse tipo de ação.

\section{QUALIFICAÇÃo ProfISSIONAL}

A qualificação profissional nas organizações permite obter resultados para os indivíduos, para suas equipes de trabalho e também para as instituições. Essa qualificação pode ocorrer de diversas formas, desde a contratação de estagiários e pessoas em primeiro emprego até ações de capacitação, como treinamentos em serviço ou investimentos em cursos realizados dentro ou fora da organização. Quando uma organização investe no aumento do grau de escolarização dos seus colaboradores - como o exemplo do Programa Educação do Trabalhador realizado pelo Serviço Social da Indústria [SESI] também está oferecendo uma oportunidade de qualificação.

Não há dúvida de que educação e trabalho são conceitos inter-relacionados. A ligação da formação profissional com o sistema educacional também é fundamental, porque o trabalho é uma forma de inserção na sociedade. As universidades e os cursos técnicos são os dois principais elos entre educação e formação profissional, mas o debate atual sobre o tema é mais abrangente e inclui também a educação básica. No Brasil, a Lei de Diretrizes e Bases da Educação prevê que a educação básica precisa dar condições de o cidadão progredir no trabalho: "A educação básica tem por finalidade desenvolver o educando, assegurar-lhe a formação comum indispensável para o exercício da cidadania e fornecer-lhe meios para progredir no trabalho e em estudos posteriores" (Lei n. 9.394, 1996).

$\mathrm{Na}$ verdade, a educação para o trabalho é vista como forma de promover maior eqüidade social e menores discrepâncias na acirrada luta por um espaço no mercado de trabalho (Departamento 
Intersindical de Estatística e Estudos Socioeconômicos [DIEESE], 1998). Se ela está ou não conseguindo cumprir essa sua função integradora na sociedade, é uma questão a ser debatida. Aranha (2001, p. 282) reforça o papel transformador atribuído à educação, quando analisa que ela tem sido entendida por governantes, empresários, dirigentes e consultores de agências internacionais como um dos aspectos essenciais na superação do subdesenvolvimento e na integração dos países periféricos à competitividade do mercado internacional e na redução do desemprego.

Segundo Bastos (2006), a qualificação profissional pode ser compreendida como poderosa explicação para o êxito ou as restrições das pessoas e mesmo dos países em transitarem por esse cenário turbulento de reestruturação produtiva e da globalização. O autor defende a idéia de que Indivíduo, Escola, Empresa e Estado estão implicados no diagnóstico e equacionamento dos desafios de qualificação que emergem na contemporaneidade. Para Bastos (2006), apesar da grande diversidade que marca os usos do conceito de qualificação, eles podem ser sintetizados em três grandes concepções: (a) como um conjunto de características das rotinas de trabalho, expressa empiricamente como tempo de aprendizagem no trabalho ou por capacidades adquiríveis por treinamento; (b) como decorrência do grau de autonomia do trabalhador e, por isso, oposta ao controle gerencial; (c) como construção social complexa, contraditória e multideterminada.

As três concepções apontadas por Bastos (2006) encontram-se presentes na prática organizacional; porém, no presente estudo, será considerada a concepção de qualificação profissional como construção social complexa, contraditória e multideterminada, sendo caracterizada não somente por ações de educação corporativa, mas também pelas experiências profissionais da pessoa, uma vez que, mesmo sem participar de nenhuma capacitação formal, a vivência de um estágio, trabalho como aprendiz ou primeiro emprego também constituem oportunidades de qualificação.

Porém o fato de adotar essa definição mais abrangente para qualificação, incorporando aspectos como o trabalho aprendiz, não reduz a importância e a forte ligação entre os conceitos de qualificação e treinamento. Aranha (2001) aponta como características da formação profissional, dada nas empresas, o caráter funcional e a intenção de se atingir objetivos em curto prazo. Essa definição aproxima-se do conceito de T\&D apresentado por Vargas (1996, p. 127):

treinamento e desenvolvimento são a aquisição sistemática de conhecimentos capazes de provocar, a curto ou longo prazo, uma mudança na maneira de ser e de pensar do indivíduo, através da internalização de novos conceitos, valores ou normas e da aprendizagem de novas habilidades.

A semelhança entre os conceitos de qualificação profissional e de T\&D no mundo das organizações também se confirma na definição de Wexley $(1984$, p. 520), para quem "treinamento é um esforço planejado de uma organização para facilitar a aprendizagem de comportamentos funcionais".

Além disso, cumpre considerar que, confirmando a tendência apontada na literatura de T\&D - de que a aprendizagem se torne um fenômeno mais aberto - as empresas vêm buscando outros espaços para o desenvolvimento da atividade formativa, tornando a formação um processo múltiplo, com ênfase para a aprendizagem contínua. Gherardi e Nicolini (2002) esclarecem que a aprendizagem como prática envolve a participação ativa em um conjunto de atividades com indivíduos que reconhecem esta participação como competência. Ou seja, não basta que as organizações ofereçam oportunidades; os trabalhadores precisam participar dessas atividades de forma ativa e reconhecer que elas lhes permitem o desenvolvimento de competências.

Em função dessa busca pela aquisição e manutenção de competências, nos últimos anos, as organizações têm investido cada vez mais em ações de TD\&E. São vários os autores que apontam o crescimento mundial do investimento em ações de capacitação (Dolezalek, 2004; Dowling \& Welch, 2005; Salas \& Cannon-Bowers, 2001; Velada, Caetano, Michel, Lyons, \& Kavanagh, 2007). De fato, a área de treinamento tem-se tornado estratégica (Pilati, 2006; Salas \& Cannon-Bowers, 2001) para as organizações, não só por serem as áreas mais diretamente relacionadas à capacitação profissional ofertada pelas organizações, mas também pela importância da área de TD\&E para a competitividade das organizações. 
O aumento dos investimentos e da importância da área de TD\&E para as organizações têm ampliado também o interesse na avaliação dessas ações (Borges-Andrade, 2002), com demanda por demonstrações de que os esforços feitos na área estão produzindo resultados positivos e impactando o desempenho dos funcionários e da organização como um todo. Na mesma linha, Raelin e Coghlan (2006) destacam que a maneira historicamente consagrada de os gerentes aprenderem tem sido por meio de treinamentos ou ações educacionais em sala de aula. Porém os autores ressalvam que, apesar do grande investimento feito em treinamento de executivos (mais de 12 bilhões de dólares por ano nos Estados Unidos), é crescente a preocupação com o baixo retorno dessas ações, estimando que menos de 5\% da aprendizagem seja, de fato, transferida para o trabalho. Ou seja, as organizações estão cada vez mais conscientes de que não basta investir em ações de qualificação, é preciso certificar-se dos efetivos resultados obtidos com elas. Para Larangeira (2002), existem dois caminhos para avaliar o grau de qualificação de uma ocupação: um objetivista e um construtivista. No objetivista, são levados em consideração critérios como o tempo necessário ao aprendizado da função, o tipo de conhecimento exigido e o grau de autonomia no seu desempenho. No construtivista, a qualificação obedeceria a critérios históricos e não-técnicos, como parte de um processo por meio do qual relações sociais são reproduzidas: a construção da qualificação, nessa perspectiva, seria, portanto, um processo de criação de distinções.

Porém, em alguns casos, a qualificação é compreendida como forma de reduzir desigualdades, pois, conforme sinalizam Sousa, Santana e Deluiz (1999), a educação hoje traz consigo uma vinculação direta com a ascensão social, tal qual era preconizado pela Teoria do Capital Humano, ou seja, quanto maior a escolaridade, maior a chance de conseguir um posto de trabalho em um mundo em que o trabalho é cada vez mais escasso. Assim, a educação para o trabalho é vista como forma de promover maior eqüidade social e menores discrepâncias na acirrada luta por espaço no mercado de trabalho (DIEESE, 1998). No caso do Brasil, a própria Constituição Federal, em seus artigos $6^{\circ}$ e $205^{\circ}$, estabelece a educação e o trabalho como direitos sociais.

“Art. $6^{0}$. São direitos sociais a educação, a saúde, o trabalho, a moradia, o lazer, a segurança, a previdência social, a proteção à maternidade e à infância, a assistência aos desamparados, na forma desta Constituição".

“Art. $\mathbf{2 0 5}^{\circ}$. A educação, direito de todos e dever do Estado e da família, será promovida e incentivada com a colaboração da sociedade, visando ao pleno desenvolvimento da pessoa, seu preparo para o exercício da cidadania e sua qualificação para o trabalho" (Constituição da República Federativa do Brasil, 1988).

No mundo das organizações, as ações educacionais configuram-se como estratégia operacional na busca da qualidade e produtividade: polivalência, enriquecimento das tarefas, aumento da responsabilidade dos trabalhadores (Aranha, 2001). Nesse sentido, a definição se aproxima muito das definições de Treinamento [T], Desenvolvimento [D] e Educação [E] adotadas nas organizações. Enquanto treinamento seria a aquisição sistemática de atitudes, conceitos, conhecimentos, regras e habilidades que resultam em melhoria do desempenho no trabalho (Goldstein, 1991), desenvolvimento é visto como ações de aprendizagem voltadas para o crescimento individual, sem relação com um trabalho específico (Nadler, 1984). A diferença essencial, conforme ressalta Borges-Andrade (2002), é que as ações de treinamento visam produzir melhorias no desempenho das pessoas, enquanto as ações de desenvolvimento são mais abrangentes, compreendendo aspectos que vão além do desempenho no trabalho e estão relacionadas ao crescimento dos treinandos.

Para Vargas (1996, p. 127),

treinamento e desenvolvimento são a aquisição sistemática de conhecimentos capazes de provocar, em curto ou longo prazo, uma mudança na maneira de ser e de pensar do indivíduo, por meio da internalização de novos conceitos, valores ou normas e da aprendizagem de novas habilidades.

A definição de Vargas para treinamento e desenvolvimento é bastante ampla, permitindo a própria a inclusão de conceitos como educação e formação profissional. Se, por um lado, falta na definição de 
Vargas uma ligação direta do processo de T\&D com o mundo do trabalho, de forma a evidenciar o próprio objetivo do sistema de $\mathrm{T} \& \mathrm{D}$, por outro a definição da autora apresenta um aspecto fundamental nesse processo: o estabelecimento da condição de que não basta haver "aquisição sistemática de conhecimentos" (Vargas, 1996, p. 127), é preciso que esses sejam "capazes de provocar mudança na maneira de ser e de pensar do indivíduo" (p. 127). A definição de Vargas (1996) permite supor que, se não houver mudança, não há que se falar em T\&D.

$\mathrm{O}$ aspecto que merece destaque é que as demandas por capacitação e as exigências do mundo do trabalho fizeram com que esses dois conceitos (Treinamento e Desenvolvimento) não fossem mais suficientes para compreender o conjunto das ações de capacitação presentes nas organizações, sendo necessário acrescentar o conceito de Educação. Para Nadler (1984), Educação compreende os eventos de aprendizagem que capacitam o indivíduo a atuar em postos de trabalho específicos em futuro próximo. Assim, a área passou a denominar-se TD\&E. Assim, o processo de qualificação profissional envolve ações de TD\&E, mas pode ir além dela, uma vez que está relacionado à aprendizagem humana.

De acordo com Abbad e Borges-Andrade (2004), a aprendizagem é um processo psicológico que faz referência a mudanças que ocorrem no comportamento do indivíduo, não resultantes unicamente da maturação, mas de sua interação com o contexto. Os autores explicam que, na linguagem comum, o ato de aprender se relaciona com: adquirir, tomar, reter, segurar, pegar, agarrar, prender e assimilar e que, na linguagem técnica aprender se refere também a aplicar no ambiente a competência adquirida, em diferentes contextos e situações.

A Aprendizagem Humana em Organizações pode ser de dois tipos: aprendizagem natural - a que ocorre por tentativa e erro, imitação, observação etc. - e aprendizagem induzida - aquela obtida por meio de situações cuidadosamente planejadas e estruturadas para isto (Abbad \& Borges-Andrade, 2004). Para esta pesquisa foram consideradas as duas possibilidades, pois se investigaram não só as ações de Treinamento, Desenvolvimento e Educação [TD\&E], mas também outras situações em que a aprendizagem natural está presente, como a contratação de estagiários, jovens aprendizes e pessoas em primeiro emprego.

Vargas e Abbad (2006) apresentam uma síntese dos conceitos relacionados à capacitação profissional nas organizações, com uma figura bastante ilustrativa, reproduzida a seguir.

\section{Figura 1: Ações de Indução de Aprendizagem em Organizações}

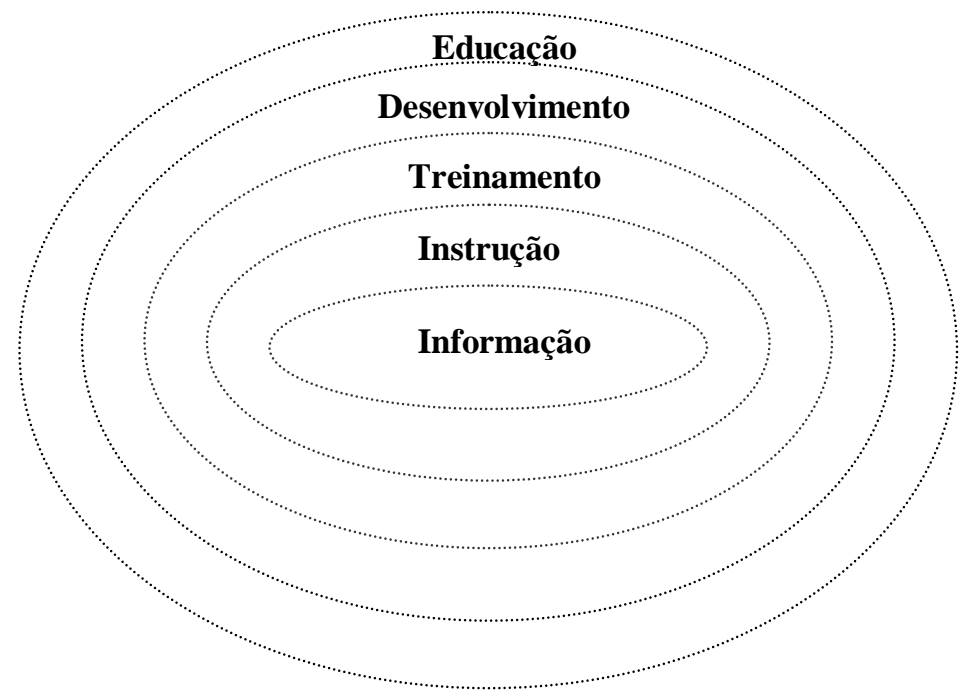

Fonte: adaptado de Vargas e Abbad (2006, p. 14). 
As autoras consideram como Educação programas de média e longa duração, como cursos técnicos profissionalizantes, graduação e pós-graduação. Já o conceito de Desenvolvimento corresponde a ações educacionais de apoio a programas de qualidade de vida no trabalho, orientação profissional, autogestão da carreira e similares, incluindo oficinas, seminários, cursos, palestras etc. O Treinamento, por sua vez, compreende ações educacionais de curta e média duração que objetivem melhorias imediatas de desempenho. A instrução inclui orientações com base em objetivos instrucionais e, em geral, é realizada com apoio de cartilhas, roteiros, manuais etc. Por fim, a Informação é menos sistematizada, referindo-se a ações educacionais de curta duração, desde aulas a aulas, a manuais e roteiros.

Um aspecto que merece destaque do ponto de vista conceitual é que a qualificação profissional envolve pelo menos três atores sociais: o governo, os trabalhadores e as empresas. Para o governo, a qualificação profissional representa uma forma de assegurar a produtividade e competitividade do país; para os trabalhadores, representa autonomia e auto-valorização; e para as empresas a qualificação profissional está associada à própria sobrevivência e à produtividade e à qualidade dos produtos e serviços prestados. Nesse sentido, os três atores sociais podem buscar qualificação profissional, assumindo o custo desse investimento. Cabe, contudo, delimitar que, para este trabalho, serão consideradas as ações de qualificação proporcionadas pelas organizações, seja por meio de cursos mesmo fora da organização - ou de uma oportunidade para pessoas que ainda não têm outras experiências de trabalho.

\section{MÉTODO}

O objetivo da presente pesquisa indicou a utilização de metodologia quantitativa, com aplicação de questionários estruturados (survey), pois a idéia era realizar um mapeamento das oportunidades de capacitação oferecidas pelas organizações no Brasil. Para a realização do survey foram adotados rígidos procedimentos internos de controle, a fim de garantir a eficiência no levantamento de campo e a fidedignidade dos resultados. Assim, a construção do instrumento de coleta de dados passou por um processo de elaboração e validação com as seguintes etapas: (a) elaboração inicial dos itens; (b) realização do pré-teste em 16 UFs; (c) discussão do instrumento final com a presença dos pesquisadores que aplicaram o pré-teste.

O pré-teste foi aplicado por 16 pesquisadores, sendo um questionário por unidade federada e com representação nas 5 regiões brasileiras. O principal objetivo do pré-teste é verificar se as questões estão claras para todos os tipos de respondentes e identificar itens que necessitavam de aperfeiçoamento.

Em relação à amostra, optou-se por amostragem probabilística, com desenho de amostra por conglomerado (ou amostra por área). Ou seja, as organizações participantes da pesquisa não serão escolhidas individualmente, mas como organizações pertencentes a um grupo (com estratificação de unidade federada e município). As pesquisas por conglomerado são muito utilizadas na prática, porque, para um mesmo custo, pode-se trabalhar com amostra maior do que amostra aleatória simples. Por isso, embora as amostras por conglomerado trabalhem com grupos mais heterogêneos que as amostras aleatórias simples, a relação custo-benefício oferecida pelas amostragens por conglomerado são melhores, porque elas apresentam menor erro-padrão por unidade monetária de custo (Mattar, 1996).

Como se optou pela amostra por conglomerado, o entrevistador não teve de controlar características como tamanho da organização, setor de atuação e tipo de organização, embora esses aspectos sejam considerados e utilizados para as análises cruzadas. Assim, a escolha das organizações participantes foi feita por meio de amostra sistemática, que é uma variação da amostra aleatória simples, com as vantagens de ser mais simples e rápida. Como lista das organizações foi considerada a lista telefônica mais recente de cada município; em alguns casos foi necessário trabalhar com listas eletrônicas, por ter 
sido abolido o sistema de listas impressas. Assim, em cada município os procedimentos adotados foram os seguintes: (a) determinação do número total de organizações (universo); (b) definição do intervalo amostral (universo dividido pelo tamanho da amostra desejada); (c) seleção de um número aleatório entre 1 e o intervalo amostral, que identifica o primeiro elemento da amostra; (d) seleção dos demais elementos da amostra, a partir da adição do número ao intervalo amostral. Como havia possibilidade de desatualizarão da lista telefônica, foram selecionadas $50 \%$ a mais de organizações em cada município que constituíram a reserva para possíveis substituições.

O estabelecimento do tamanho da amostra também levou em conta o plano de análise dos dados, pois alguns tipos de análise não podem ser feitos com amostras muito reduzidas. Mattar (1996) indica que para uma análise com tabulação cruzada (análise bivariada) costumam ser necessários mais de 500 questionários. Porém, como a amostra idealizada foi de 1.150 questionários, pôde-se fazer esse tipo de análise.

A coleta de dados foi realizada por 23 pesquisadores - um por unidade federada - e quatro supervisores de campo. Cada entrevistador recebeu, portanto, uma lista com 15 organizações por município a ser pesquisado e aplicou 10 questionários em cada cidade, sem seguir rigorosamente um sistema de quotas. Porém, para cada organização, foram anotadas as características de tamanho, setor de atuação e número de empregados, para facilitar o processo de supervisão da coleta de dados.

O tamanho da amostra estimado foi de 1.150 questionários, abrangendo 115 municípios. Em cada unidade federada foram pesquisadas cinco cidades. Para a escolha delas, em cada uma das unidades federadas, adotou-se o critério de porte de acordo com o número de habitantes fornecido pelo Instituto Brasileiro de Geografia e Estatística - IBGE (2004): (a) Pequeno porte I: até 20.000 habitantes; (b) Pequeno porte II: de 20.001 a 50.000 habitantes; (c) Médio porte: de 50.001 a 100.000 habitantes; (d) Grande porte: de 100.001 a 900.000 habitantes; e (e) Metrópole: mais de 900.000 habitantes. Assim, para esta pesquisa, foram adotados os mesmos critérios do IBGE e, em relação às metrópoles, como nem todo Estado dispõe de uma, foram incluídas as capitais de todos eles, além de dois municípios de Pequeno Porte e dois de Médio Porte. Considerando esses critérios, foi feito o sorteio aleatório dos municípios a serem pesquisados. No caso do Distrito Federal, como não há municípios, foram pesquisadas, além de Brasília, cinco outras regiões administrativas.

\section{RESULTADOS}

Os resultados da pesquisa serão divididos em duas seções: perfil das organizações pesquisadas e análise do índice de oportunidades de qualificação oferecidas por essas organizações e das variáveis correlacionadas a esse índice. Após a apresentação dessas duas seções, os resultados serão discutidos nas considerações finais do presente artigo.

\section{Perfil das Organizações Pesquisadas}

Nas 1.146 organizações pesquisadas, a média de número de funcionários por organização foi de 29,6, mas essa média é pouco representativa, porque as respostas variaram entre 0 a 3.200 e o desviopadrão foi bastante elevado $(145,9)$. A mediana foi 5 funcionários. A maioria das organizações $(70,4 \%)$ possui até 10 funcionários e $21,2 \%$ possui entre 11 a 50 funcionários. Portanto as organizações com mais de 50 funcionários representam menos de $10 \%$ do total.

Os setores de atuação foram diversificados, com uma distribuição de 92,2\% para o setor terciário, $6 \%$ secundário, $1,8 \%$ do setor primário. A representação do capital estrangeiro foi mínima, de $0,7 \%$. Todo o restante refere-se ao capital majoritariamente nacional. Em relação à classificicação em setor público, privado ou terceiro setor, a distribuição foi respectivamente de 7,9\% público, $91,1 \%$ privado e $1 \%$ do terceiro setor. 
A maioria das organizações pesquisadas possuem até 10 anos de mercado $(54,1 \%)$. As organizações que possuem mais de 20 anos representam apenas um quinto do total pesquisado. Em relação ao porte, a maioria das organizações pesquisadas é classificada como microempresa $(56,7 \%)$; o segundo maior percentual ficou com as pequenas empresas, 20,7\%. A média empresa e a grande empresa correspondem a $12,7 \%$ e $8 \%$ da amostra, respectivamente.

Quase a metade das pessoas que responderam a essa pesquisa eram sócias/proprietárias (47,2\%) das empresas; os administradores/diretores vieram em segundo lugar, porém com índice 1,75 vezes inferior (27\%); os profissionais e/ou gerentes da área de Recursos Humanos representaram 8,5\% do total da amostra. Foi significativo também o percentual dos que exercem outros cargos $(17,4 \%)$. Em relação ao gênero das pessoas que responderam à pesquisa, a maior representação ficou com o masculino, $55 \%$.

Em relação ao ensino formal dos funcionários que trabalham na organização, foi solicitado o tipo de educação que cada pessoa tinha, pautado pelos diferentes níveis de escolarização, de forma a abranger toda a gama existente na organização. Para a resposta, os pesquisados deveriam considerar o último nível concluído por seus empregados. Constatou-se que $82,8 \%$ das organizações têm empregados com ensino médio e 45,6\% têm empregados com ensino fundamental. As organizações com empregados graduados também apresentou índice elevado (40\%). Poucas organizações têm trabalhadores analfabetos $(7,3 \%)$, e pós-graduados apenas $(11,3 \%)$.

\section{Análise das Oportunidades de Qualificação Oferecidas pelas Organizações Brasileiras}

Para avaliar as oportunidades de qualificação oferecidas pelas organizações brasileiras, foi elaborada a seguinte questão: Esta organização contribui com a qualificação profissional de seus funcionários? que tinha como alternativas de resposta: Sim, contratando estagiários; Sim, com programas de jovens aprendizes; Sim, contratando pessoas em primeiro emprego; Sim, com treinamentos em serviço; Sim, oferecendo cursos dentro ou fora da organização; e Não, não temos nenhuma dessas ações de qualificação. A questão permitia mais de uma resposta, na busca da identificação dos mecanismos mais adotados pelas organizações para oferecer oportunidades de qualificação aos seus colaboradores. Os maiores percentuais ficaram com Treinamento em Serviço $(46,4 \%)$ e Cursos Dentro ou Fora da Organização (42,3\%). A terceira resposta mais freqüente (Contratação de Pessoas em Primeiro Emprego) ficou com percentual 1,45 vezes menor, atingindo $29,1 \%$, seguida pelas organizações que disseram contratar estagiários $(18,9 \%)$ ou fazer parte do programa de jovens aprendizes $(8,6 \%)$. Merece destaque o fato de $26,4 \%$ das organizações afirmarem não ter nenhuma ação de qualificação. A Figura 2 mostra as oportunidades de qualificação oferecidas nas organizações brasileiras. 
Figura 2: Oportunidades de Qualificação

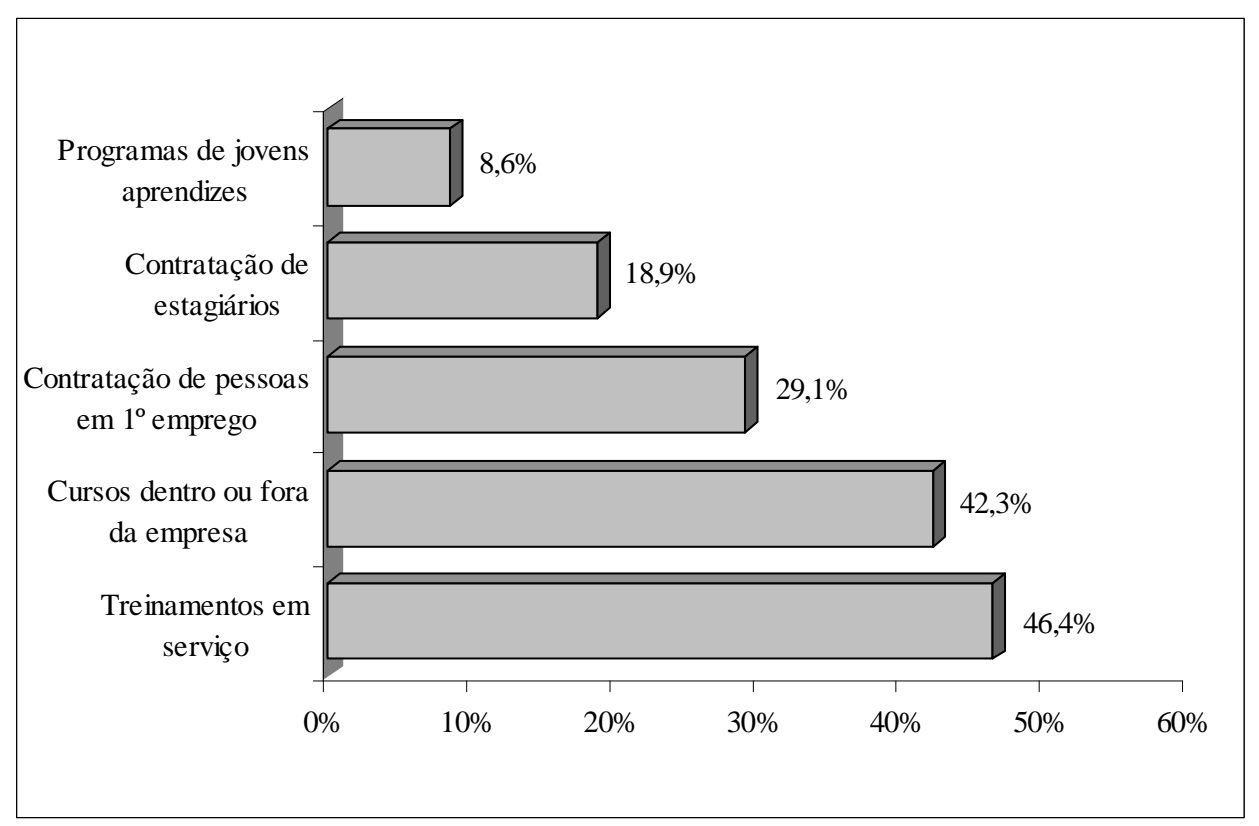

Com o intuito de melhor analisar os resultados dessa pesquisa foi criado, a partir das respostas a esta questão, um Índice de Oportunidades de Qualificação. Como critério de codificação, foi atribuído valor um para cada uma das cinco possíveis respostas positivas à pergunta sobre as oportunidades de qualificação profissional: contratação de jovens aprendizes, de estagiários, de pessoas em primeiro emprego, de treinamentos em serviços ou de cursos oferecidos dentro ou fora da organização. Como as três primeiras opções, relativas à contratação de pessoas que ainda não têm formação e/ou experiência, se referem, em geral, à oportunidade de aprendizagem natural (e, em alguns casos, motivada exclusivamente pela redução da folha de pagamentos e dos encargos trabalhistas), essas respostas receberam peso 1, enquanto a realização de treinamentos em serviços ou de cursos oferecidos dentro ou fora da organização receberam peso 2. Assim, esse índice consistiu no somatório ponderado das resopstas, podendo variar de 0 a 7 (sendo o zero correspondente às organizações que não oferecem nenhuma oportunidade de qualificação e 7 correspondente a organizações que contratam estagiários, jovens aprendizes, pessoas em primeiro emprego, além de realizar treinamentos em serviços e oferecer cursos dentro ou fora da organização).

Considerando esse procedimento, os resultados são preocupantes: a média nacional do Índice de Oportunidades de Qualificação é de 2,3, com desvio-padrão de 1,8, mediana 2,0 e o valor modal igual a zero. A análise da distribuição de freqüência mostra uma curva assimétrica à esquerda, caracterizando reduzidas oportunidades de qualificação profissional, conforme mostra a Figura 3. 


\section{Figura 3: Histograma de Freqüencia do Índice de Oportunidades de Qualificação Profissional}

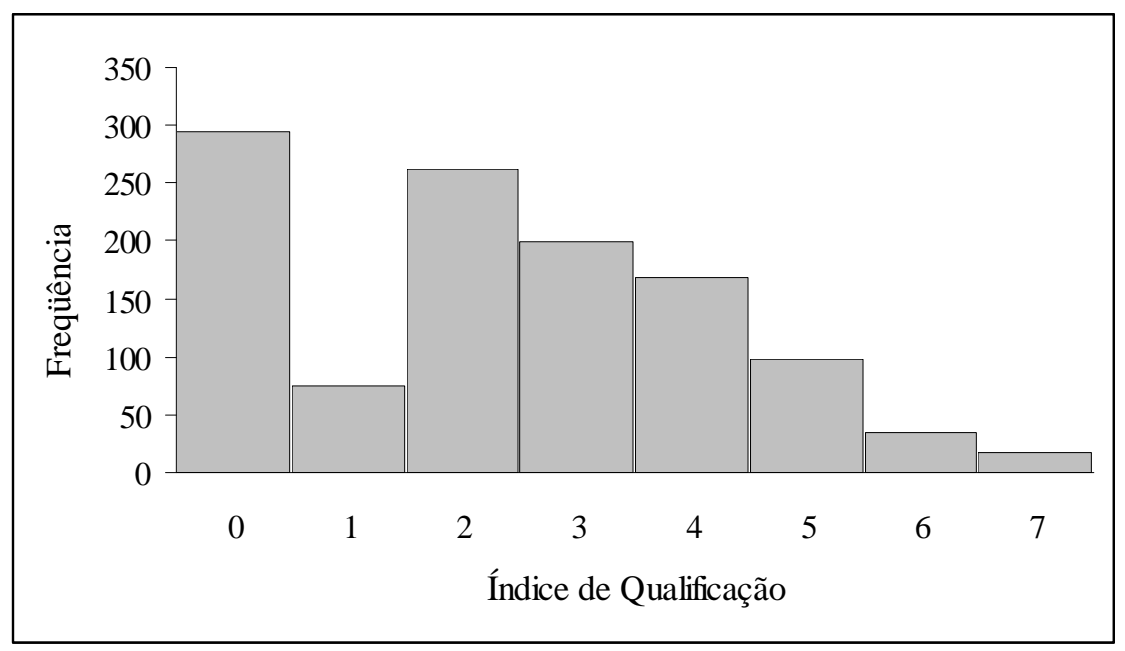

Como a contratação de jovens aprendizes foi muito reduzida, optou-se por testar como ficariam as análises, desconsiderando-se esse item como uma das possíveis oportunidades de qualificação profissional. Porém as medidas de tendência central e de dispersão praticamente não sofreram alterações (média $=2,2$; e os valores de desvio-padrão, mediana e moda iguais à análise que considera esse item). Assim, optou-se por manter a contratação de jovens aprendizes no Índice de Oportunidades de Qualificação Profissional.

Em relação às correlações, pelo fato de o Índice ser uma medida não-paramétrica, utilizou-se a Correlação de Spearman. Foram encontradas correlações significativas e positivas do Índice de Oportunidades de Qualificação Profissional com o número de funcionários das organizações, com o tempo de mercado delas e com o porte delas, conforme mostra a Tabela 1. Porém não foi encontrada correlação entre o porte do município e o Índice de Oportunidades de Qualificação Profissional, possivelmente pelo fato de a amostra ser por conglomerado, fazendo com que os municípios pequenos, médios e grandes tivessem participação ponderada no estudo.

\section{Tabela 1: Resultados da Correlação do Índice de Oportunidades de Qualificação com Algumas Variáveis}

\begin{tabular}{|l|l|l|}
\hline Pares de Variáveis & Correlação & Significância \\
\hline Índice de Oportunidades de Qualificação x N Ne empregados das organizações $^{\text {Inde }}$ & 0,42 & 0,00 \\
\hline Índice de Oportunidades de Qualificação x Porte das organizaços & 0,29 & 0,00 \\
\hline Índice de Oportunidades de Qualificação X Tempo de mercado das organizações & 0,14 & 0,00 \\
\hline
\end{tabular}

Esses resultados mostram que a correlação mais forte se dá com o número de empregados das organizações, seguido pelo porte delas. A correlação do Índice de Oportunidades de Qualificação Profissional com a influência do tempo de atuação no mercado, embora significativa e positiva, apresentou uma coeficiente baixo $(0,14)$.

Esses dados mostram que quanto maior a organização, e sobretudo quantos mais empregados ela tem, maiores as chances de oferecer oportunidades de qualificação. Este resultado já era esperado, mas o dado é preocupante, porque a grande maioria das organizações no Brasil têm até 5 funcionários e são de pequeno porte.

Outra análise que foi realizada a fim de melhor compreender como está o mapeamento de oportunidades no cenário nacional foi a realização de uma análise de variância (ANOVA ONE-WAY), 
para verificar se havia diferença significativa entre as médias dos Índices de Oportunidades de Qualificação nas cinco regiões brasileiras. O resultado da ANOVA mostrou que as diferenças são significativas, como mostra a Tabela 2.

Tabela 2: Resultados da Análise de Variância do Índice de Oportunidades de Qualificação Considerando a Variável Região

\begin{tabular}{|l|l|l|l|l|l|}
\hline & $\begin{array}{l}\text { Soma dos } \\
\text { Quadrados }\end{array}$ & $\begin{array}{l}\text { Graus } \\
\text { Liberd. }\end{array}$ & $\begin{array}{l}\text { Média dos } \\
\text { Quadrados }\end{array}$ & F & $\begin{array}{l}\text { Signifi- } \\
\text { cância }\end{array}$ \\
\hline Entre grupos & 140,4 & 4 & 35,1 & \multirow{2}{*}{0,8} \\
\cline { 1 - 4 } Nos grupos & 3713,2 & 1141 & 3,3 & 0,00 \\
\hline Total & 3853,6 & 1145 & & \\
\hline
\end{tabular}

Considerando que a diferença entre as médias regionais foi significativa, realizou-se o cruzamento (análise bivariada) dos resultados do Índice de Oportunidades de Qualificação, de acordo com a Região. A seguir é apresentada uma tabela com os percentuais obtidos em cada Região, considerandose a classificação de Índice Baixo, Médio e Alto de Oportunidades de Qualificação (Tabela 3). Para esta análise, foram considerados índices baixos os que ficaram entre 0 e 2, médios os valores 3 e 4 , e altos as organizações que obtiveram valores entre 5 e 7 no Índice de Oportunidades de Qualificação.

\section{Tabela 3: Índice de Oportunidades de Qualificação, Segundo a Região}

\begin{tabular}{|l|l|l|l|}
\hline Região & $\begin{array}{l}\text { Índice } \\
\text { Baixo }\end{array}$ & $\begin{array}{l}\text { Índice } \\
\text { Médio }\end{array}$ & $\begin{array}{l}\text { Índice } \\
\text { Alto }\end{array}$ \\
\hline Norte & $42,3 \%$ & $45,6 \%$ & $12,1 \%$ \\
\hline Nordeste & $67,0 \%$ & $25,2 \%$ & $7,8 \%$ \\
\hline Sudeste & $53,0 \%$ & $29,5 \%$ & $17,5 \%$ \\
\hline Sul & $44,7 \%$ & $37,3 \%$ & $18,0 \%$ \\
\hline Centro-oeste & $51,2 \%$ & $33,2 \%$ & $15,6 \%$ \\
\hline
\end{tabular}

Os resultados do cruzamento do Índice de Oportunidades de Qualificação com a Região mostram que a Região Nordeste é a que apresenta as mais baixas oportunidades de qualificação, enquanto as Regiões Sul e Sudeste apresentam índices mais altos. É preciso que esses resultados sejam analisados com cuidado do ponto das políticas públicas de incentivo à qualificação, sob pena de ser acirrada a já considerável diferença de desenvolvimento que existe entre as regiões brasileiras.

Também foi realizada ANOVA ONE-WAY para verificar se há diferenças significativas entre as oportunidades de qualificação oferecidas por órgãos públicos e privados e também pelo setor de atuação: primário, secundário e terciário. Os resultados motraram que não houve diferença significativa das oportunidades de qualificação por setor; porém há significativa diferença nas organizações públicas e privadas, conforme mostra a Tabela 4.

Tabela 4: Resultados da Análise de Variância do Índice de Oportunidades de Qualificação Considerando a Variável Tipo de Organização (Pública, Privada ou do Terceiro Setor)

\begin{tabular}{|l|l|l|l|l|l|}
\hline & $\begin{array}{l}\text { Soma dos } \\
\text { Quadrados }\end{array}$ & $\begin{array}{l}\text { Graus } \\
\text { Liberd. }\end{array}$ & $\begin{array}{l}\text { Média dos } \\
\text { Quadrados }\end{array}$ & F & $\begin{array}{l}\text { Signifi- } \\
\text { cância }\end{array}$ \\
\hline Entre grupos & 49,1 & 2 & 24,5 & & \multirow{2}{*}{7,4} \\
\hline Nos grupos & 3804,6 & 1143 & 3,3 & 001 \\
\hline Total & 3853,6 & 1145 & & & \\
\hline
\end{tabular}


Considerando que a diferença entre as médias do Índice de Oportunidades de Qualificação nas organizações públicas, privadas e do terceiro setor foi significativa, realizou-se o cruzamento (análise bivariada) dos resultados do Índice de Oportunidades de Qualificação, de acordo com a o tipo de organização. A seguir é apresentada uma tabela com os percentuais obtidos em cada tipo de organização, considerando-se a classificação de Índice Baixo, Médio e Alto de Oportunidades de Qualificação (Tabela 5).

\section{Tabela 5: Índice de Oportunidades de Qualificação, Segundo o Tipo de Organização}

\begin{tabular}{|l|c|c|c|}
\hline Tipo de organ. & Índice baixo & Índice médio & Índice alto \\
\hline Pública & $42,2 \%$ & $38,9 \%$ & $18,9 \%$ \\
\hline Privada & $55,9 \%$ & $31,5 \%$ & $12,6 \%$ \\
\hline
\end{tabular}

Os resultados do cruzamento do Índice de Oportunidades de Qualificação com o tipo de organização mostram que as organizações privadas apresentam oportunidades de qualificação mais baixas que as públicas. Porém, como as organizações públicas costumam ter um número maior de funcionários, é possível que a variável tamanho da organização estivesse influenciando esses resultados. Assim, realizou-se uma nova análise na qual foram consideradas apenas as organizações com mais de 100 funcionários, sendo 22 públicas e 30 privadas. Essa análise evidenciou que, controlada a variável número de empregados, o setor privado oferece mais oportunidades de qualificação, pois o índice de baixo investimento foi quase o dobro nas públicas (41,2\%, contra $21,3 \%$ das empresas privadas). $\mathrm{Na}$ mesma linha, os investimentos em qualificação considerados altos foram maiores nas organizações privadas (41\%, contra $29,4 \%$ nas públicas). Outra análise realizada foi a do cruzamento do porte da organização com o Índice de Oportunidades de Qualificação, conforme mostra a Tabela 6.

Tabela 6: Índice de Oportunidades de Qualificação Segundo o Porte das Organizações

\begin{tabular}{|l|l|l|l|}
\hline Porte da organização & $\begin{array}{l}\text { Índice } \\
\text { Baixo }\end{array}$ & $\begin{array}{l}\text { Índice } \\
\text { Médio }\end{array}$ & $\begin{array}{l}\text { Índice } \\
\text { Alto }\end{array}$ \\
\hline Indústria caseira & $90,9 \%$ & $9,1 \%$ & $0 \%$ \\
\hline Micro-empresa & $62,8 \%$ & $29,2 \%$ & $8,0 \%$ \\
\hline Pequena empresa & $53,9 \%$ & $33,2 \%$ & $12,9 \%$ \\
\hline Média empresa & $35,9 \%$ & $42,3 \%$ & $21,8 \%$ \\
\hline Grande empresa & $23,3 \%$ & $37,8 \%$ & $38,9 \%$ \\
\hline
\end{tabular}

Pela análise da Tabela 6, pode-se perceber que as indústrias caseiras são as que têm os índices mais baixos de oportunidades de qualificação profissional, seguidas pelas microempresas. Por outro lado, as grandes empresas são as que têm índice mais alto de oferecimento de oportunidades de qualificação profissional. Um aspecto que merece destaque nessa análise é o fato de a maioria das organizações brasileiras ser de micro e pequeno porte, o que significa que as chances oferecidas atingem um número menor de pessoas.

Também foi realizada a análise bivariada do tempo de atuação da organização no mercado com o Índice de Oportunidades de Qualificação, para verificar se o amadurecimento das organizações resulta ou não em maior investimento na qualificação da sua mão-de-obra. A Tabela 7 mostra os resultados obtidos, considerando-se a classificação do Índice de Oportunidades de Qualificação como baixo, médio e alto. 


\section{Tabela 7: Índice de Oportunidades de Qualificação Segundo o Tempo de Atuação das Organizações}

\begin{tabular}{|l|c|c|c|}
\hline $\begin{array}{c}\text { Tempo de atuação } \\
\text { no mercado }\end{array}$ & $\begin{array}{c}\text { Índice } \\
\text { Baixo }\end{array}$ & $\begin{array}{c}\text { Índice } \\
\text { Médio }\end{array}$ & $\begin{array}{c}\text { Índice } \\
\text { Alto }\end{array}$ \\
\hline De 1 a 4 anos & $64,7 \%$ & $26,3 \%$ & $8,9 \%$ \\
\hline De 5 a 8 anos & $58,2 \%$ & $28,9 \%$ & $12,9 \%$ \\
\hline De 9 a 12 anos & $54,4 \%$ & $35,8 \%$ & $9,8 \%$ \\
\hline De 13 a 21 anos & $51,2 \%$ & $36,1 \%$ & $12,7 \%$ \\
\hline Mais de 22 anos & $46,0 \%$ & $32,6 \%$ & $21,4 \%$ \\
\hline
\end{tabular}

Do cruzamento mostrado acima pode-se concluir que quanto menor o tempo de atuação no mercado, menos as organizações proporcionam oportunidades de qualificação profissional. Assim, as organizações com até 4 anos são as que apresentam os índices mais baixos, enquanto as que têm mais de 22 anos são as que apresentam os índices mais altos de oportunidades de qualificação profissional.

Finalmente, foi realizada a análise do número de funcionários da organização com o Índice de Oportunidades de Qualificação, conforme mostra a Tabela 8.

Tabela 8: Índice de Oportunidades de Qualificação Segundo o No de Funcionários

\begin{tabular}{|l|c|c|c|}
\hline $\begin{array}{c}\mathbf{N}^{\mathbf{0}} \text { de funcionários das } \\
\text { organizaçóes }\end{array}$ & $\begin{array}{c}\text { Índice } \\
\text { Baixo }\end{array}$ & $\begin{array}{c}\text { Índice } \\
\text { Médio }\end{array}$ & $\begin{array}{c}\text { Índice } \\
\text { Alto }\end{array}$ \\
\hline De 1 a 5 funcionários & $70,1 \%$ & $23,5 \%$ & $6,4 \%$ \\
\hline De 6 a 15 funcionários & $46,5 \%$ & $38,1 \%$ & $15,4 \%$ \\
\hline De 16 a 100 funcionários & $31,5 \%$ & $47,2 \%$ & $21,3 \%$ \\
\hline Mais de 100 funcionários & $21,2 \%$ & $34,6 \%$ & $44,2 \%$ \\
\hline
\end{tabular}

A análise deste cruzamento mostra que as organizações com até 5 funcionários são as que menos promovem oportunidades de qualificação para seus colaboradores, com um percentual consideravelmente inferior daquele das que têm mais de 5 funcionários e com diferença muito expressiva para as organizações com mais de 100 funcionários. Essa análise deixa claro que as pessoas terão mais chances de obter qualificação profissional se trabalharem em organizações com maior número de empregados. O problema aqui, como aconteceu na análise de outras variáveis, é que estas (organizações com maior número de funcionários) é justamente o estrato menos freqüente no Brasil.

\section{CONSIDERAÇÕES FINAIS}

Não há dúvida de que um novo olhar tem sido dado à questão da qualificação profissional no Brasil. As organizações têm sofrido pressões por competitividade e a qualificação da equipe de trabalho é um dos diferenciais na luta pela sobrevivência ou na busca de ofertar produtos e serviços de qualidade. Porém, apesar de toda a ênfase dada à questão da qualificação, e do discurso crescente acerca de sua importância, o mapeamento realizado na presente pesquisa mostra que as oportunidades de qualificação profissional oferecidas pelas organizações no Brasil ainda são restritas. Considerando a tipologia apresentada por Vargas e Abbad (2006) sobre os conceitos relacionados à capacitação profissional nas organizações, observa-se que muitas organizações estão centradas ainda na instrução e na informação, que são ações menos sistematizadas e que não envolvem o planejamento de eventos específicos de capacitação. A ocorrência de ações de treinamento, desenvolvimento e de educação, 
propriamente dita, são mais raras, sendo mais encontradas em determinadas organizações, sobretudo as mais antigas e de maior porte.

Os resultados mostram que menos da metade das organizações pesquisadas oferecem qualquer tipo de curso, dentro ou fora da organização; e um quarto das organizações não têm nenhuma ação de qualificação profissional. Numa escala de zero a sete, o índice médio de oportunidades de qualificação, considerando o cenário nacional, é de 2,3 (com desvio-padrão de 1,8). O que se percebe é que as oportunidades são oferecidas por um perfil específico de organizações, a saber: organizações de grande porte, com mais de 100 funcionários, mais de 22 anos de atuação no mercado e localizadas nas regiões Sul e Sudeste. Em relação ao setor de atuação, as organizações públicas apresentaram mais oportunidades de qualificação considerando-se a amostra geral; mas, quando se compara organizações do mesmo porte (acima de 100 funcionários), observa-se que as oportunidades de capacitação oferecidas pelo setor privado são muito maiores.

Os resultados dessa pesquisa mostram, portanto, que é preciso refletir acerca da qualificação profissional no Brasil, visto que, se o panorama atual for mantido, a tendência é de agravamento das diferenças entre as regiões e com poucas oportunidades para a maioria dos trabalhadores que estão insertos em organizações de micro ou pequeno porte e com poucos funcionários. Se, por um lado, já se sabe que não apenas no Brasil, mas em vários países se encontra essa realidade de as empresas menores não investirem em Treinamento ou investirem muito pouco, por outro lado, há grande contingente de pessoas trabalhando nessas organizações e que precisam de qualificação, até mesmo para melhorar a qualidade da mão-de-obra no Brasil.

Portanto é preciso que os três atores sociais responsáveis pela qualificação profissional - governo, trabalhadores e empresas - busquem ampliar as oportunidades de qualificação profissional, pois isso é necessário para assegurar a produtividade e competitividade do país, para permitir autonomia e autovalorização da mão-de-obra e para a própria sobrevivência e a qualidade e produtividade das empresas. Embora essa pesquisa tenha sido delimitada para verificar os investimentos feitos pelas organizações, isso não significa que os trabalhadores e o governo possam eximir-se da responsabilidade de contribuir para a modificação desse quadro.

Não há dúvida de que a qualificação profissional exerce importante papel de garantia de manutenção do trabalho e da empregabilidade. Sobre este último conceito, Aranha (2001, p. 281) descreve que "por empregabilidade entende-se a responsabilização do trabalhador pela obtenção e manutenção do seu emprego, por meio de um processo contínuo de formação e aperfeiçoamento". Porém, embora seja ponto pacífico que o trabalhador precisa ser um agente ativo na busca de seu auto-aperfeiçoamento, a ênfase cada vez maior na construção pessoal da empregabilidade merece reflexões, pois a educação não pode deixar de ser uma política social de pleno emprego e caracterizar-se apenas como uma busca individual.

Assim, os resultados da pesquisa sugerem uma reflexão acerca das políticas públicas de qualificação, no sentido de atender também a trabalhadores que estão no setor privado, especialmente os que se encontram nas situações com menores oportunidades de qualificação.

Mas, além disso, é necessário construir uma nova cultura de qualificação e requalificação nas organizações. É preciso que os empresários e os profissionais de recursos humanos compreendam que, quando se investe em qualificação profissional, os resultados não ficam restritos ao indivíduo que participa da ação, pois há difusão de conhecimento, o que permite desenvolver estruturas cognitivas comuns para a aplicação no trabalho daquilo que foi aprendido.

A presente pesquisa apresenta algumas limitações como o fato de não dimensionar a quantidade de cursos oferecidos pelas organizações - seja considerando o indicador do valor do investimento, seja o de número de horas de capacitação. Porém, embora se tenha tentado obter essas informações, não se obtiveram dados consistentes, porque muitas organizações não têm esses registros e porque outras os consideram como informação estratégica. Isso fez com que o Índice de Oportunidades de Qualificação Profissional ficasse restrito ao oferecimento pelas organizações de cada um dos tipos de qualificação, 
independentemente do quanto cada uma investe. Mesmo assim, as correlações evidenciam a validade do índice, na medida em que confirmam que organizações maiores, com mais funcionários, com maior tempo de atuação no mercado e nas Regiões Sul e Sudeste são as que mais investem em ações de qualificação profissional.

Outra limitação do presente estudo refere-se ao fato de não se poder detalhar mais a realidade das práticas de TD\&E no Brasil, uma vez que apenas $10 \%$ da amostra foi formada por organizações com mais de 50 funcionários, reconhecidamente, aquelas que realizam mais ações de capacitação. Para ampliar as análises relativas às práticas de TD\&E, propõe-se que seja feito um novo estudo, apenas com organizações com mais de 50 funcionários, apresentando um panorama nacional. A respeito desse possível panorama, vale destacar a pesquisa realizada por Campos et al. (2004), com empresas paulistas de médio e grande porte. $\mathrm{O}$ estudo das autoras mostrou que as organizações utilizam cursos diversos oferecidos no mercado e outros planejados pela própria empresa para atender às necessidades individuais dos empregados. Porém, mesmo considerando o universo apenas de empresas paulistas com mais de 100 funcionários, Campos et al. (2004) verificaram que, apesar de ter aumentado a importância da área de treinamento, ela ainda não tem os dados sistematizados, faltando informações sobre a proporção entre salários e treinamento, o número de dias de capacitação por funcionário, entre outras.

Os resultados desta pesquisa confirmam as análises de Manfredi (2000) e de Girão (2001). Manfredi (2000) pondera que estamos em um momento de criação e reelaboração de várias concepções de educação profissional que retratam, de forma diferenciada, os interesses dos grupos sociais envolvidos nesses processos de transformação social. Girão (2001), por sua vez, considera que as camadas sociais têm acesso a processos diferenciados de formação profissional e que algumas camadas nem sequer são atingidas por esse sistema de qualificação de trabalhadores.

Considerando a relação entre o porte das organizações e os investimentos em oportunidades de qualificação, o presente estudo confirma os achados de outras pesquisas. Uma pesquisa sobre a atuação da área de Treinamento e Desenvolvimento foi realizada com 30 empresas polonesas (Elbadri, 2001). Nesse estudo a amostra foi dividida de acordo com o número de empregados: 0-99, 100-999, 1.000-5.000, e mais de 5.000 empregados. Os resultados da pesquisa de Elbadri (2001) mostram que a, exemplo do que acontece no Brasil, também na Polônia as empresas de menor porte são particularmente relutantes em relação ao treinamento. O autor também cita outros estudos que encontraram resultados semelhantes como o de Vickerstaff, Murphy, Fuller e Hayward (1991). Um importante survey foi realizado por Wong, Marshall e Thwaites (1997), investigando em 1.992 empresas de pequeno e médio porte as necessidades de treinamento. Os resultados encontrados por Wong apontam que apenas um sexto das organizações pesquisadas realizam planejamento de treinamento e uma pequena proporção delas têm um orçamento específico para ações de capacitação. Na mesma linha, o estudo realizado na Europa por Bassanini et al. (2005) mostra que nos 26 países pesquisados há um comportamento padrão das organizações - tanto as consideradas inovadoras como as não-inovadoras - de haver maior percentual de pessoas capacitadas nas organizações com mais de 250 empregados do que nas organizações que têm entre 10 e 50 empregados. Finalmente, um estudo realizado por Fowler (1990, citado em Elbadri, 2001), nos Estados Unidos aponta um cenário distinto. Enquanto as pequenas organizações são resistentes às ações de treinamento, $62 \%$ dos presidentes das 264 maiores companhias norte-americanas afirmam que construir e manter uma força de trabalho qualificada é o desafio mais importante da década.

Porém, diante dos achados da presente pesquisa e do que se encontrou na revisão de literatura internacional, cabe perguntar em que medida as organizações brasileiras estão mesmo investindo na qualificação da sua mão-de-obra ou até que ponto a importância do desenvolvimento e manutenção de competências está mais presente no discurso que nas práticas organizacionais. Também é preciso discutir o perfil de trabalhador que está recebendo oportunidades de qualificação e o perfil de trabalhadores que ficam de fora dessas iniciativas, cabendo a reflexão do que cumpre fazer para resgatá-los. Em síntese, é preciso que os três atores sociais participantes deste processo trabalhadores, empresas e governo - desenvolvam estratégias e mecanismos que permitam transformar 
em realidade o discurso de qualificação profissional, cada vez mais presente nos debates organizacionais e sociais.

Artigo recebido em 28.08.2007. Aprovado em 24.06.2008.

\section{REFERENCIAS BIBLIOGRÁFICAS}

Abbad, G., \& Borges-Andrade, J. E. (2004). Aprendizagem humana em organizações e trabalho. In J. C. Zanelli, J. E. Borges-Andrade, \& A. V. B. Bastos (Orgs.). Psicologia, organizações e trabalho no Brasil. Porto Alegre: Artmed.

Aranha, A. V. S. (2001). Formação profissional nas empresas: locus privilegiado da educação do trabalhador?. In S. M. Pimenta \& M. L. Côrrea (Orgs.). Gestão, trabalho e cidadania. Belo Horizonte: Autêntica Editora.

Bassanini, A., Booth, A., Brunello, G., De Paola, M., \& Leuven, E. (2005). Workplace training in Europe. Recuperado em 02 março, 2008, de http://www.iser.essex.ac.uk/epunet/2005/docs/pdf/papers/brunello.pdf

Bastos, A. V. B. (2006). Trabalho e qualificação: questões conceituais e desafios postos pelo cenário de reestruturação produtiva. In J. E. Borges-Andrade, G. S. Abbad, \& L. Mourão (Orgs.). Treinamento, desenvolvimento e educação em organizações e trabalho:fundamentos para a gestão de pessoas. Porto Alegre: Artmed.

Borges-Andrade, J. E. (2002). Desenvolvimento de medidas em avaliação de treinamento. Revista Estudos de Psicologia, 7(Especial), 31-43.

Constituição da República Federativa do Brasil de 1988. (1998). Diário Oficial da União, no 191-A, Brasília, 5 de outubro de 1988. Recuperado em 28 abril, 2007, de http://www.planalto.gov.br/CCIVIL_03/Constituicao/Constituiçao.htm

Campos, K. C. L., Barduchi, A. L. J., Marques, D. G. Ramos, K. P., Santos, L. A. D., \& Becker, T. J. (2004). Avaliação do sistema de treinamento e desenvolvimento em empresas paulistas de médio e grande porte. Psicologia Reflexão e Cítica, 17(3), 435-446.

Departamento Intersindical de Estatística e Estudos Socioeconômicos. (1998). Formação profissional : um novo espaço de negociação. São Paulo: Autor.

Dolezalek, H. (2004). Training annual industry report. Training Magazine, 42(10), 20-28.

Dowling, P. J., \& Welch, D. E. (2005). International human resource management: Managing People in a Multinational Context (4th ed.). Mason, $\mathrm{OH}$ : Thomson South-Western.

Elbadri, A. N. A. (2001). Training practices of polish companies: an appraisal and agenda for improvement. Journal of European Industrial Training, 25(2-3-4), 69-79.

Girão, I. C. C. (2001). Representações sociais de gênero: suporte para as novas formas de organização do trabalho. In S. M. Pimenta \& M. L. Côrrea (Orgs.). Gestão, trabalho e cidadania. Belo Horizonte: Autêntica Editora.

Goldstein, I. L. (1991). Training in work organizations. In M. D. Dunnette \& L. M. Hough (Orgs.). Handbook of industrial and organizational psychology (2nd ed., pp. 507-619). California: Consulting Psychology Press. 
Larangeira, S. M. G. (2002). Verbete qualificação. In A. D. Cattani (Org.). Trabalho e tecnologia: dicionário crítico (4a ed.) Petrópolis: Vozes.

Lei n. 9.394, de 20 de dezembro de 1996 (1996). Estabelece as diretrizes e bases da educação nacional. Leis de Diretrizes e Bases da Educação Nacional. Brasília. Recuperado em 28 junho, 2007, de http://portal.mec.gov.br/seed/arquivos/pdf/tvescola/leis/lein9394.pdf

Manfredi, S. M. (2000). A reestruturação do trabalho e os desafios para a formação profissional no Brasil - Projetos e perspectivas dos diferentes atores sociais. Anais do Congresso Latinoamericano de Sociologia del Trabajo, Buenos Aires, Argentina, 3.

Mattar, F. N. (1996). Pesquisa de marketing (Edição compacta). São Paulo: Atlas.

Nadler, L. (1984). The handbook of human resources development (pp. 1-47). New York: Wiley.

Gherardi, S., \& Nicolini, D. (2002). Learning in a constellation of interconnected practices: canon or dissonance?. Journal of Management Studies, 39(4), 419-436.

Pilati, R. (2006). História e importância de TD\&E. In J. E. Borges-Andrade, G. S. Abbad, \& L. Mourão (Orgs.). Treinamento, desenvolvimento e educação em organizações e trabalho: fundamentos para gestão de pessoas (pp. 343-358). Porto Alegre: Artmed.

Raelin, J. A., \& Coghlan, D. (2006). Learning and action research developing managers as learners and researchers: using action. Journal of Management Education, 30(5), 670-689

Salas, E., \& Cannon-Bowers, J. A. (2001). The science of training: a decade of progress. Annual Review Psychology, 52, 471-499.

Sousa, D. B. de, Santana, M. A., \& Deluiz, N. (1999). Trabalho e educação: centrais sindicais e reestruturação produtiva no Brasil. Rio de Janeiro: Quartet.

Vargas, M. R. M. (1996). Treinamento e desenvolvimento: reflexões sobre seus métodos. Revista de Administração, 31(2), 126-136.

Vargas, M. R. M., \& Abbad, G. (2006). Bases conceituais em treinamento, desenvolvimento e educação - TD\&E. In J. E. Borges-Andrade, G. S. Abbad, \& L. Mourão (Orgs.). Treinamento, desenvolvimento e educação em organizações e trabalho:fundamentos para a gestão de pessoas. Porto Alegre: Artmed.

Velada, R., Caetano, A., Michel, J. W., Lyons, B. D., \& Kavanagh, M. J. (2007). The effects of training design, individual characteristics and work environment on transfer of training. International Journal of Training and Development, 11(4), 282-294.

Vickerstaff, S., Murphy, M., Fuller, M., \& Hayward, E. (1991). Training and the small businesses. Canterbury: University of Kent

Wexley, K. N. (1984). Personal training. Annual Review Psychology, 35, 519-51.

Wong, C., Marshall, J., \& Thwaites, A. (1997). Management training in small and medium-sized enterprises: methodological and conceptual issues. The International Journal of Human Resource Management, 8(1) 44-65. 